\title{
Tantas memórias - ou um difícil passeio pelos modos de pensar a memória: possibilidades, textos, atores
}

\author{
Jerusa Pires Ferreira \\ Professora e pesquisadora do Programa de Pós-graduaçāo em Comunicação e Semiótica da PUC-SP
}

\section{RESUMO}

$\mathrm{O}$ artigo refere vários sentidos de memória, segundo diferentes pontos de vista c observa que memória nunca é recuperação objetiva e completa do que já passou. Memória é base nào só para fenômenos biológicos, mas também para a identidade cultural e para a tradiçăo; sua seletividade é tanto uma proteção para os indivíduos e sociedades, como ć caminho para a cultura. Entre outros títulos, refere-se com mais ênfase ao livro de Mônica R.F. Nunes, A Memória na Midia, do qual apresenta um brevíssimo resumo, como sendo indispensável aos estudos sobre Memória. Faz o mesmo em relaçào ao livro de F. Colombo, publicação antiga e já bastante conhecida, $O s$ Arquives Imperfeitos.

Palavras-chave: Memória. Arquivos. Cultura. Diversidade textual

\section{ABSTRACT}

This article deals with the many meanings stemming from Memory, according to different points of view. It assumes that Memory never is a complete, objective recovery of what ceased to be. Memory is a basis not only for biological phenomena, but also for cultural identity and tradition; its selectivity is as much a protection for the individuals and societies as it is a way to culture. Among other titles analyzed, this study refers, in particular, to the books "A Memória na Midia", from Monica F.F Nunes, and "Os Arquivos Imperfeitos", by F. Colombo, considering them as indispensable to the study of Memory,

Key words: Memory. Files. Culture. Textual diversity 
1 - ZUMTHOR, Paul Traduçāo de Jerusa Pires Ferreira e Amálio Pinheiro. Sāo Paulo: Companhia das Letras, 1993.

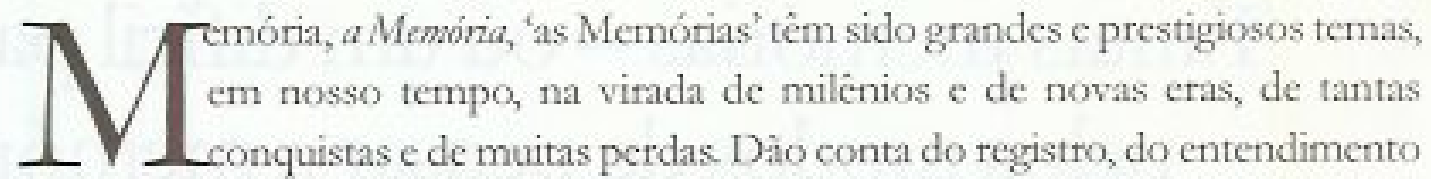
daquilo que se busca processar, desvelar, mas têm sido também rótulos que abrigam qualquer coisa, panacéia, e canteiro de equivocos. Afinal, sob o tótulo de memória cabe tanta coisa...

Há nas pessoas todo um desejo de guardar e recuperar o que se extravia na vertigem. Mas a memória disso ou daquilo só pode ser exercida em plenitude relativa ou $\mathrm{cm}$ suas incompletudes, recriaçòes $\mathrm{e}$ até impedimentos. Assim há tambem memória como sustentação de "identidades", rede de conhecimentos que se projetam ao passado c ao futuro concomitantemente, $\mathrm{cm}$ movimento pendular.

Por sua vez a Memónia, fenômeno material c corpóreo, psíquico e ainda fenómeno de cultura, enquanto categoria, é um modo especial de presentificar a vida em muitos atos e formas especificas do lembrar, que pode vir do recordar, ao re-lembrar ou evocar e dai por diante, lembrar esquecendo ou simplesmente esquecer.

Quanto a memória biológica, e cla não pode deixar de ser aqui trazida, se desenvolve num terreno $\mathrm{cm}$ que tudo é o jogo dinâmico entre seleçào, codificação, transferência. E entào tudo será memória e scu par complementar o esquecimento.

Penso, aliás que a vida é uma luta pela memória, contando sempre com os vários tipos de esquecimento, o restaurador, o devastador, ou simplesmente o olvido c o silêncio que antecipam a morte.

Podemos falar de modos de ser da memória, das suas falhas e de seus excessos, lembrando que a memória prodigiosa num individuo era um fato comprometedor, por exemplo, perante a Igreja c seus Inquisidores, como nos aponta tão bem Paul Zumthor no seu livro fundamental A L etra c a Voq:[1] Era atribuido a este fato todo um poder diabólico. Nào scria dificil de imaginatse o embaraço $\mathrm{c}$ os perigos para as heterodoxias de um tal arquivo vivo, por um lado denunciador por outto transmissor. Até hoje, em linguagem policial, fala-se de queima de arquivos, quando se elimina alguém cuja memória detém fatos e seria capaz de trazê-los à tona.

Para a tradiçào oral, a memória é espaço, lugar, e a própria matéria construtiva de tudo o que se cria. Ela é o encontro da tradição com o presente e com aquilo que se projeta ao futuro. Ė ai há a memória acionada em presença, interativa e fundamental, no estabelecimento da pactuaçào que torna possivel o reconhecimento de um repertório e do ato criador. 
As memórias contadas (anamneses), imaginadas, comparecem desde sempre na literatura e na poesia (afinal nunca é demais tepetir que a memória é a màe de todas as musas), e são muitas vezes a própria literatura e a poesia. Identificando-se fortemente com o processo criador e suas matérias primas, Miguel'Torga, escritor português, chama de Dias da Criaģăo [2] alguns dos livros de memórias que escreveu, à mancira do Génesis bíblico. Augusto Roa Bastos um dos maiores escritores de nosso continente, em seu livro Yo d/ Supromo, [3] atribui à memória, inclusive à memória viva na palavra otal, a capacidade de poder reverter a tirania da letra e dos déspotas que a transformaram em lei.

A literatura apóia na grande memória pessoal/coletiva discursos que trazem, $\mathrm{m}$ interação, o reavivar ou o esquecer, $\mathrm{cm}$ processos contínuos.

Assim nào podemos também deixar de lado velocidades e ritmos, os labirintos, a memória das formas e a dos gêneros, a memótia fantasmática. Há ainda a comentar a força de toda uma memória subterrânea, daquela que se desenrola como algum tipo de resistência a que foi recalcado e perseguido e que recrudesce com uma vitalidade sem par.

Estas reflexōes fazem parte do conjunto $\mathrm{em}$ que se fundamentaram os ensaios e estudos contidos $\mathrm{em}$ meu recente livro, Armadilhas da Memoiria. [4]

Mas há também na literatura, na própria construção da memória, o discurso sobre ela, aquele que procura comprecnder alcances e limites da apreensão memorial. Temos neste caso, entre outros o fascinante livro de Ismail Kadaré [5] sobre a memória e seus registros, que ele tào sabiamente batizou de Le Dossier H.

Não será um dossiê o lugar de uma reuniào, mas o da memória aprisionada?

Ele nos conta aí o episódio da presença de dois pesquisadores que vêm de Harvard para descobrir c gravar os rapsodos albaneses que eles acreditavam deter uma epopéia pré-homérica. $\mathrm{Na}$ trama romanesca que se desenvolve, pudemos acompanhar como, de fato, o fizcram. Na véspera de partir porém, defrontaramse com o que não esperavam. Um certo "monge", alucinado e defensor da tradiçào, entra no alojamento dos pesquisadores e destrói tudo, considerando que não se pode registrar c levar consigo a memótia de um povo. Impressionante episódio que nos oferece para pensar um ato imobilista c retrógrado, mas, ao mesmo tempo, considerar os paradoxos de nossa transformaçaio, em que tanto se destrói e sc perde, quando se pretende captar. Ou quando a captação se transforma em apropriação que desterritorializa e desfigura.

Poderí ser bem abrangente mas sempre será incompleto um discurso sobre a memória, do mesmo jeito que a memória abarca e despreza fatos e coisas e a outras faz renascer vivificadas e perenes
2- TORGA, Miguel. Diário. $4^{3}$ ediçāo. Coimbra: Coimbra Editora, 1957.

3- ROABASTOS, Augusto, Yo el Supremo. Cuba:

Casa de las

Aménicas, 1979.

4 - FERREIRA, J.P. Armadilhas da Memória. São Pawlo: Atelis Editorial, 2004,

5 - KADARE, Ismail. Le Dossier H. Paris: Gallimard, 1989. 
6 - FERRARI

NUNES, Mônica

Rebeca. A Memória

na Miclia: a

Evoluçắo dos

Memes de Afeto.

Sīo Paulo:

Annablume/

Fapesp, 2001.

7- YATES, Frances

A. L'art de la

Mémoire. Pans:

Gallimard, 1987.
A propósito do livro instigante e denso, A Memória na Mídia, [6] de Mónica Rebecca Ferrari Nunes e do prefácio que escrevi para ele, tenho de confessar que isto representou para mim um desafio e que o fiz com muita dificuldade.

Estava, por um lado, procurando caminhos restauradores e, por outro, descobertas. Sempre que começava, se oferecia claramente toda a dificuldade do percurso, tudo o que traz de complexo o fato de estar pensando a memória, buscando uma sintese possivel. E mais complicado ainda foi estar diante do conjunto memória, corpo, e mídia, compreendendo a passagem por algumas destas incursòes $\mathrm{e}$ de tantas outras. Procuraria mostrar que a originalidade deste trabalho é, entre outras coisas, o fato de estabelecer conexões, de pensar a constituiçăio da memória em termos cognitivos, incursionando pelo neurológico, a partir das formulaçòes de Antonio Damásio, em seu livro $O$ erro de Descarles. Acompanha-se a continuidade da memória $\mathrm{cm}$ suas unidades afetivas e neurológicas mínimas - os memes, que por sua vez, vão responder pela presença de determinädos tópicos na Cultura. Constata a autora que certas recorrências de segmentos $\mathrm{e}$ de situações são acionadas pelos agenciadores $\mathrm{c}$ transmissores de cultura midiática, a partir de atos replicadores, atingindo-se, na recepção, essas unidades $\mathrm{em}$ condiçōes de serem assimiladas.

Tem portanto, em seu trabalho, alguns apoios fundamentais, como o livro básico de Frances Yates, As Artes da Memónia [7] do qual faz às vezes a paráfrase e exercita o comentário.

Desenvolve a idéa de meme que explica, com clareza, nos oferecendo a possibilidade de enfrentar as relaçōes entre a produção de memória e o corpoA partir de uma perspectiva evolucionista assumida, situa nos memes e na memória aspectos da mutação biológica, ao longo da história.

Reflete e discorre sobre a memória na contemporaneidade e, ao invés de pensar em resgate, numa interpretação que contemple o viés saudosista do ato memorial, considera-o em projeçòes e replicações sucessivas e nos ritmos e precipitaçòes c atualizaçōes da memótia.

Trata dos arquivamentos, dos espaços e das configuraçôes, procurando ultrapassar, no entanto esta dimensão. $A$ autora consegue estabelecer alguns princípios pelos quais um outro corpo (mais que metaforicamente assumido como tal) ou seja o dos textos de cultura, e depois a imprensa e a midia, consegue se estabelecer enquanto sofisticada organização da memória. As notícias nos aparecem como sistematização de códigos culturais transmissíveis, e sua leitura aponta para a cvolução do biológico e também para o campo mítico. O corpomidia com suas leis de permanéncia, o corpo da notícia e da midia ali colocados à luz da teoria semiótica. 
Nos belos títulos que dá a seus capitulos, constrói o que poderiamos chamar uma poéfica da mentória. Ali estão contemplados os scgredos, a memória da dor, os lugares c imagens a cla referidos, as memórias do medo, do sangue e de outros elementos que remetem à vida e à morte.

Em sua densidade, este livro discute os paradigmas rumo à memória artificial ou às memórias artificiais, e o que interessa nào é concordar ou discordar dos passos dados pela a autora e pesquisadora mas observar o seu achado que contempla o dinamismo inerente a todo texto de cultura. Dentro desta perspectiva, procura seguir nas recorrèncias e na presença afetiva de situaçòes recuperadas e intensificadas, os operadores afetivos deste corpo/ midia. Ao observar a construção da noticia na midia, capta os aspectos de rememoração e os de projeçào e plancjamento. Ao pretender uma semiose do ato memorial transmissivel, reúne, com prudência, contribuçcōes que vão da biologia aos sistemas de informaçio. Creio ser um livto indispensável aos estudiosos dessa área que nos pede sempre explotaçào e audácia.

Foi então que vivi a incrivel experiência de reler, e com dobrada atenção, o livro Os Arguinos Imperfeitos [8] de F'austo Colombo. Ele nos mostra no século XX uma autêntica vocaçio para a Memória, e nos situa (como não podia deixar de ser, diante do aumento de informação) face a uma espécie de mania arquivistica, que permeia conjuntamente a cultura e a evoluçào tecnológica: a gravaçào e o arquivamento e a seqüencia de seus atos decodificadores e tradutórios, eu diria.

I eva-nos a tecuperar algumas idéias do teórico russo Luria, [9] ao falar da espacializaçào da memória c aqui, da tecnologia ao homem, e aos espaços disponiveis para os diversos tipos de memória.

E. bem atraente a aproximação que faz dos arquivos telemáticos às antigas formas de memorizaçio (mnemê), transmitidas e sedimentadas nas Artes da Mcmória, aproximação feita também com muita oportunidade pela pesquisadora Mary Carruthers. [10]

Para Giordano Bruno, o saber mnemómnico enforma o mundo que assume sempre com maior intensidade os contornos da lembrança, da memória espacializada e traduzida. Colombo về a concepçâo de Bruno reviver nas concepçòes informáticas de nossa era. Ẻ nos apresenta o desafio da concepção cabalística e da configuraçio de certos icones que se transformam em talimàs.

Tendo a memória como chave de leitura, nos traz algo de fundamental, a idéia de que a estruturaçào do saber é a estruturação do mundo, e nos coloca diante da potência de uma coisa que ele denomina forma-memória.

Passando por uma série de questòes da maior importância, nos encontramos
8- COLOMBO, Fausto. Os Arquivos Imperfeitos. Säo Paulo: Perspectiva, 1991.

9- VIGOTSKII, L.S, LUAIA, A.R. Linguagem, Desenvolvimento $\mathrm{e}$ Aprendizagem. Tradução de Maria da Penha Villalobos. São Paulo: licone: Editora da Universidade de São Paulo, 1988.

10 - CARRUTHERS, Mary. The Book of the Mernory. London: Cambridge University Press, 1990. 
11. RICOEUR, Paul. La Mémoire, I'histoire, T'oubli. Panis: Edvitions du Seuil, 2000.
12 - FERREIRA, $J$. P. "José Calasans: um mestre, um pesquisador, um pioneiro". Revista Projeto História do Programa de Estudas PósGraduados $\mathrm{cm}$ História da PUC/SP. no. 23. São Paulo: Educ, 2001. diante do eu-arquivo para quem conta muito a conservação e a recuperação, a luta contra o esquecimento possivel, enquanto apagamento dos traços memoriais.

Por outro lado, faz a apologia daquele esquecimento restaurador que comentamos em outra seqüencia do nosso livro já referida.

\section{O TEMA E SEUS PERSONAGENS}

Quando nos aproximamos de um tema, o elegemos como questào central, e vamos desvendando-o aos poucos, há surpresas e encontros extraordinários mas, só depois de alguma experiència, conseguimos abrir pistas, aproximar o que antes estava disperso, estabclecer analogias. Podemos experimentar (aliás sempre e prioritariamente) a percepção poética, que nos traz o impossível de ser conseguido por outras vias. Toda elaboração é lenta, $e$ imagine-sc quando um tema tem a complexidade de significaçòes de $A$ Memória, desde sempre objeto de tantos filósofos, pensadores, escritores, cientistas...

Recentemente ficaria muito impressionada com o notável índice de sistematização c de entendimento classificador c hermenéutico dos fenómenos ligados à memória, pela leitura do livro de Paul Ricocur Ia Memoir, Thistoire. Foubli. [11] Sobretudo por cle começar estabclecendo, a partir de Aristóteles, as diferenças entre a memória contada (anamese) e a que se apresenta codificada na intensificacio de seus processos para lembrar (mnemê).

Como comentei antes, para a tradicio oral a memótia é mais que apoio, é matéra prima, é lugar, detonaçào, ponto de partida. I embrar ć um ato que arregimenta falas e gestos, corpo e mente, o legado dos mortos e a presença dos vivos, é coesão e transformaçào possivel. Mas é sobretudo garantia de precisào e entendimento. Por isso mesmo é cm certa medida ficçào, preenchimento c uma sucessâo de atos tradutórios imediatos.

Por sua vez, e sem descartar curiosidade ou estranha afinidade, pesquisadores vão se aproximando e trocando experiências, construindo uma espécie de rede...

Não por acaso recordo (aliás no pleno sentido afetivo e retroativo do termo) meu orientador de mestrado, o historiador José Calasans (UFBa), [12] um pioneito dos estudos de História Oral no Brasil, trazendo ele próprio a memória de um grande texto oral que presentificava criaturas e personagens, situaçoes de nossa história, icones e documentos, como é o caso da guerra de Canudos e da evocada e consccutivamente recriada figura de Antonio Conselheiro (aliás com muita razào).

A memória viva em recriaçio permanente achava espaço em sua fala que reinventava o repertório captado $\mathrm{em}$ sua infância c ao longo de sua vida. Fazia 
acompanhar o relato ou a dramatizaçāo da cena oral, acompanhando tudo com um discreto riso e um meneio de cabeça.

Aliás, a propósito disso, da performance memorial, há todo um campo a ser explorado, no que se refere à riqueza do gestual (Jogos de Memória), quando do ato de lembrar. [13] Evoco aqui a figura extraordinária do semioticista russo V.V.Ivánov, [14] uma das mais sibias criaturas que já encontrei, e que nos transmitia, em diversas ocasiōes, os seus conhecimentos, formulando questòes c evocando situaçoos, coisa que fazia de olhos fechados e acompanhando de discretos gemidos. A sua criação e transmissào memorial, correspondia toda uma realização corporal sugestiva e compativel ao esforço de lembrar, ao prazer e à dor que é a luta pela memória, que pode ser recompensa ou castigo.

Não por acaso, no doutorado teria como orientador Ruy Galvão de Andrada Coelho, [15] que aos vinte anos tinha já escrito um trabalho sobre Proust, cle próptio detentor de uma intensa cogitaçào sobre as coisas e de um discurso $\mathrm{cm}$ fluxo sobre a memória, e poderiamos falar dele mesmo como memória em discurso. Sua exposiçăo cra toda uma captação de referências.

Ele nos trouxe um acento especial para a memória que recria, que re-inventa, apelando para a percepçào gestáltica. Ou, em meio a suas reflexòes sobre a imaginaça sociológica, um dos temas de sua predileçào, nos ia levando a entender a força coesiva da memória, situando-nos diante de Maurice Halbwachs que muito admirava, procurando sempre tirar de "Os quadros scriais da memória" [16] os traços que the permitiam conectar uma memória social, se assim se puder dizer, às inserçōes do sujeito, em seus vários ritmos memoriais. Gravamos c transcrevemos algumas de suas reflexòes, em que se inscreve o forte viés de uma memória mágica, consideraçōes que vào de Dante a Giordano Bruno.

Foi também ele que nos trouxe pela primeira vez Frances Yates, e seu livro extraordinátio sobre as Artes da Memória situando espacializaçōes e fazcndo descobrir tradições tào fortes no Renascimento, como o teatro da Memória de Giulio Camilo.

Assim, e sob a atraente chamada de Paul Zumthor num surpreendente texto poético, que traduzimos c publicamos em portuguess, A Tradíño t a Esquacinnento, [17] fui adentrando as sutilezas de leitura neste território em que se constrói toda uma rede em movimento de achados e de indagaçòes.

Támbém com a memória que transmite conhecimentos sobre a magia do desempenho de dizer e da escuta, do que se fala ou se omite, do que se capta ou nào, atentos ou não para as energias que encontram rumo ou se desviam. Procurou fazer ccoar em nós a auscultação de uma espécic de "voz primotdial", pulsaçáo e vida, para ele móvel e princípio de toda poesia oral, da tradição que se faz transmissão
13- ZUMTHOR, Paw et FOY, Bruno. Jeux de Mémoire: Aspects de la Mnémotechnie Médiévale. Montreal: Les Presses de IUniversité de Montréal, 1985.

$14-C f$. SCHNAIDEFMAN, Boris (org). Semiótica Aussa. Săo Paulo:

Perspectiva, 1979.

15 - FERREIRA, J.

$P$. De uma aula de Rui Coelho: magia e memória', in: Revista Imaginário, no 2, Centro de Estudos do Imaginário da USP, 1995.

16 - HALBWACHS, Maurice. Les Cadres Sociaux de la Mémoire. Paris: Fólix Alcan, 1925.

17 - ZUMTHOF, Paut. Tradição e Esquecimento. Tradução de Senusa Pires Ferreira e Suely Fenerich. São Paulo: Hucitec, 1997. 
18 - Cf. FERREIRA, Jerusa $P$. Armadilhas da Memória. São Pacho: Ateliet Editorial, 2004.

19 - MOURA, Hudson. "Memória $e$ exilio: o cinema de Vadimir de Carvalho". Dissertaçáno de Mestrado. São Paulo: PUC/SP, 1996.

20- GAEMMAS, Algirdas J. Of Gods and Men. Indiana University Press, 1992.

21 - SELIGHMAN, Márcio. Catástrofe e Representaçăo. Săo Paufo: Escuta, 2002.
Como dissc, impressionada com a precisão de Yuri Lotman, [18] ao considerar a memória $\mathrm{cm}$ transmissão como ato seletivo, informacional e comunicacional, passaria a me preocupar intensamente com esta viagem, rumo à memótia de textos que, em sua trajetória, pensassem a memória.

Depois de publicar, Cultora e Memóna (Revista USP, n. 24), enfocando as concepçōes do mestre pensador russo de Tártu, passei a oferecer um curso com este nome no Programa de Pós em Comunicação e Semiótica da PUC-SP e já realizamos dois Colóquios "Cultura é Memória", no Núcleo de Poéticas da Oralidade, onde nos encontramos, tantas vezes, procurando as aproximaçòes possíveis entre a Memória (ato e materialidade) e as memórias nartadas, por excmplo, entre o lugare as temporalidades memoriais, e passando naturalmente por diversas linhas de concep̧̧óes e estudos sobre a Memória.

O que nos fica bem claro não é que se conclui uma passagem exaustiva ou conclusiva sobre tudo isto, mas que se constrói, em rede, toda uma cogitaçào que vai se atualizando, abrindo novas possibilidades, aproximando ou afastando discursos, apostando na possibilidade tensiva deste ou daquele aspecto, deixando que se construa todo um texto móvel, num território de imprevisibilidades.

Cabem aqui o ato comunicador levado à sua mais extrema ação, a profecia $\mathrm{c}$ o que chamei de memória do futuro, quando há todo um repertório que se projeta como fundamental e se alimenta do ato receptivo

A partir de algum tempo, por exemplo, "Memória e exilio" [19] passaram a ser um de nossos tópicos mais insistentes, respondendo inclusive por uma conexìo com os trabalhos de meu orientando Hudson Moura, que a partir do cinema de Vladimir de Carvalho situou a memória migrante, o tema da migraçào, busca de uma territorialização, conforme Gilles Deleuze, desenvolvendo sua tese de doutorado sobre 'Imagem e exílio'.

E eu rão poderia deixar de acusar aqui a importância que teve para mim o prefácio de Dan Ben Amos sobre o livro Of Gods and Men de Greimas, [20] quando ele nos mostra como o exilio é a mais forte das experièncias do século XX, e podemos avançar pelo XXI, infelizmente. $A$ deslociçảo requer o lastro da memória em toda a sua intensidade para o assentamento, e o esquecimento do trauma para a continuação dos vínculos identitários ou para a criação de novos. [21]

O rol das alusōes é infinito, mas fomos trazendo, sempre que possivel, de Jean Pierre Vernant (Mito e Pensamento entre os Gregos) a Lèvi- Strauss (O Olhar Distanciado) à conhecida contribuição de Jacques le Goff e de Picrre Nora, ao encantamento da leitura de Walter Benjamin, a Mary Carruthers pesquisadora inglesa $\mathrm{cm}$ scu Book of Memory (London, 1990), no qual ela nos aptesenta todo um recenseamento das formas de sistematizar a memória, enquanto fenômeno da arte 
e da cultura e também na diversidade de suas abordagens a Claude Filteau, a Ecléa Bosi, a Jeanne Marie Gagnebin [22] com seus belos trabalhos, de Platào a Walter Benjamin, a Miriam Chnaiderman [23] que buscou em sua tese de doutorado um viés fisiológico da memória, com os estudos de Ribot, entre tantos outros.

Conforma-se aqui uma espécie de rede (sempre muito a percorter de Freud a I acan) em que se espraia o tema, novas bibliografias e referências vào sc abrindo e, a partir delas, a inserçào de textos de cultura, tendo a memória como assentamento. O corpo biológico e o corpo extensivo dos signos, formalizados ou não, na plenitude de seus mistérios.

Aí se oferecem muitas vezes desafios, abismos, barreiras, que nem sempre conseguimos transpor, e a que não nos propusemos aqui. É nesta inquietação que estão as chaves procuradas no trato com a memória, enquanto texto de vida, de cultura e de representaçaio, mesmo quando nos colocamos diante dos desastres, dos fragmentos, das memórias atribuladas e conflituosas, do mal-estar ou da possibilidade de redençio.

Penso que aqui não seria redundante retomat o mito Borgesiano de uma viagem infinita.

\section{BIBLIOGRAFIA}

CARRUTHERS, Mary. The Book of the Memory. London: Cambridge University Press, 1990.

COLOMBO, Fausta. Os Arquivos Imperfeilos. São Paulo: Perspectiva, 1991. FERRARI NUNES, Mônica Rebeca. A Memória na Midia: a Esoluşão dos Memes de Afteta. Sào Paulo: Annablume/ Fapesp, 2001.

FERREIRA, Jcrusa. P. Armadilhas da Memória. Sào Paulo: Ateliê Editorial, 2004. "De uma aula de Rui Coelho: magia c memória", in: Revista Imaginário, no 2. Sào Paulo: Centro de Estudos do Imaginário da USP, 1995.

"José Calasans: um mestre, um pesquisador, um pioneiro", in: Revista Projeto Historia do Ptograma de Estudos Pós-Graduados em História da PUC/ SP, n. 23. Sào Paulo: Educ, 2001.

GAGNEBIN, Jeanne Marie. Sete Aulas Sobn I inguagem, Memóriae Histónia. Sào Paulo: Imago, 1997.

GREIMAS, Algirdas J. Of Gods and Mon. Indiana University Press, 1992. HN AIDERMAN, Miriam. "Esfarelando tempos nào ensimesmados", in: Revista Agora, no. 2, do Centro de Estudos cm Teoria Psicanalítica da UFRJ, julho/ dezembro de 2003 .

KADARÉ, Ismail. Le Dossier H. Paris: Gallimard, 1989. 
MOURA, Hudson. "Memória e exilio: o cinema de Vladimir de Carvalho". Dissertação de Mestrado. Sào Paulo: PUC/SP, 1996.

ROA BASTOS, Augusta. Yo e/ Supreno. Cuba: Casa de las Américas, 1979 .

RICOEUR, Paul. La Mémoire, /bistoire, lowbli. Paris: Éditions du Seuil, 2000.

SELIGHMAN, Márcio Catástroffe e Representação. São Paulo: Editora Escuta, 2002.

SCHNAIDERMAN, Boris (org). Semiótica Russa. São Paulo: Perspectiva, 1979.

TORGA, Miguel. Diário. $4^{2}$ ediçâo, Coimbra: Coimbra Editora, 1957.

YATES, Frances A. Lan de la Mémoire. Paris: Gallimard, 1987.

ZUMTHOR, Paul. A Letra e a Vơ Tradução de Jerusa Pires Ferreira e Amálio Pinheiro, Sào Paulo: Companhia das I Letras, 1993.

Tradiào e Esquecimonto. Tradução de Jerusa Pires lerreira e Sucly Fencrich. Sảo Paulo: Hucitec, 1997. ; ROY, Bruno. Jerx de Mémoire: Aspects de La Mnémotedbnie Médiévalt. Montréal: Les Presses de

l'Université de Montréal, 1985. 